University of Nebraska - Lincoln

DigitalCommons@University of Nebraska - Lincoln

Agronomy \& Horticulture - Faculty Publications

Agronomy and Horticulture Department

2010

Fine mapping of the soybean aphid-resistance gene Rag2 in soybean PI 200538

\author{
Ki-Seung Kim \\ University of Illinois \\ Curtis B. Hill \\ University of Illinois \\ Glen L. Hartman \\ University of Illinois \\ D. L. Hyten \\ USDA-ARS, Soybean Genomics and Improvement Laboratory, Beltsville, Maryland, david.hyten@unl.edu \\ Matthew E. Hudson \\ University of Illinois
}

See next page for additional authors

Follow this and additional works at: https://digitalcommons.unl.edu/agronomyfacpub

Part of the Agricultural Science Commons, Agriculture Commons, Agronomy and Crop Sciences

Commons, Botany Commons, Horticulture Commons, Other Plant Sciences Commons, and the Plant

Biology Commons

Kim, Ki-Seung; Hill, Curtis B.; Hartman, Glen L.; Hyten, D. L.; Hudson, Matthew E.; and Diers, Brian W., "Fine mapping of the soybean aphid-resistance gene Rag2 in soybean PI 200538" (2010). Agronomy \&

Horticulture -- Faculty Publications. 794.

https://digitalcommons.unl.edu/agronomyfacpub/794

This Article is brought to you for free and open access by the Agronomy and Horticulture Department at DigitalCommons@University of Nebraska - Lincoln. It has been accepted for inclusion in Agronomy \& Horticulture -Faculty Publications by an authorized administrator of DigitalCommons@University of Nebraska - Lincoln. 
Authors

Ki-Seung Kim, Curtis B. Hill, Glen L. Hartman, D. L. Hyten, Matthew E. Hudson, and Brian W. Diers 


\title{
Fine mapping of the soybean aphid-resistance gene Rag2 in soybean PI 200538
}

\author{
Ki-Seung Kim • Curtis B. Hill · Glen L. Hartman • \\ David L. Hyten • Matthew E. Hudson · Brian W. Diers
}

Received: 4 December 2009/Accepted: 26 March 2010/Published online: 8 May 2010

(C) Springer-Verlag 2010

\begin{abstract}
The discovery of biotype diversity of soybean aphid (SA: Aphis glycines Matsumura) in North America emphasizes the necessity to identify new aphid-resistance genes. The soybean [Glycine max (L.) Merr.] plant introduction (PI) 200538 is a promising source of SA resistance because it shows a high level of resistance to a SA biotype that can overcome the SA-resistance gene Ragl from 'Dowling'. The SA-resistance gene Rag2 was previously mapped from PI 200538 to a 10-cM marker interval on soybean chromosome 13 [formerly linkage group (LG) F]. The objective of this study was to fine map Rag2. This fine mapping was carried out using lines derived from 5,783 $\mathrm{F}_{2}$ plants at different levels of backcrossing that were screened with flanking genetic markers for the presence of recombination in the Rag2 interval. Fifteen single nucleotide polymorphism (SNP) markers and two dominant polymerase chain reaction-based markers near Rag2 were developed by re-sequencing target intervals and sequencetagged sites. These efforts resulted in the mapping of Rag2 to a 54-kb interval on the Williams $828 \times$ assembly (Glyma1). This Williams 82 interval contains seven predicted genes, which includes one nucleotide-binding site-
\end{abstract}

Communicated by I. Rajcan.

K.-S. Kim · C. B. Hill · M. E. Hudson · B. W. Diers $(\bowtie)$

Department of Crop Sciences, University of Illinois, Urbana, IL 61801, USA

e-mail: bdiers@illinois.edu

G. L. Hartman

USDA-ARS and Department of Crop Sciences,

University of Illinois, Urbana, IL 61801, USA

D. L. Hyten

Soybean Genomics and Improvement Laboratory,

USDA-ARS, Beltsville, MD 20705, USA leucine-rich repeat gene. SNP marker and candidate gene information identified in this study will be an important resource in marker-assisted selection for aphid resistance and for cloning the gene.

$\begin{array}{ll}\text { Abbreviations } \\ \text { INDEL } & \text { Insertion and deletion } \\ \mathrm{kb} & \text { Kilobase pair } \\ \text { MAS } & \text { Marker-assisted selection } \\ \text { MCA } & \text { Melting curve assay } \\ \text { NBS-LRR } & \text { Nucleotide-binding site-leucine-rich repeat } \\ \text { SNP } & \text { Single nucleotide polymorphism } \\ \text { STS } & \text { Sequence-tagged site }\end{array}$

\section{Introduction}

Although the soybean aphid (SA: Aphis glycines Matsumura) has a short history in the USA, the aphid has caused significant damage and has spread to most soybean growing states since its discovery in the country in 2000 (Voegtlin 2008). There is a need to identify new sources of SA resistance as diversity in SA was shown to occur in North America. Michel et al. (2009) showed the presence of diversity in SA based on simple sequence repeat (SSR) diversity and Kim et al. (2008) showed that at least two different SA biotypes exit in North America. These biotypes are biotype 1 , which was collected in Illinois and is controlled by the SA-resistance genes Ragl from Dowling and Rag in 'Jackson', and biotype 2, which originated from Ohio and can overcome these genes. Evaluations with both SA biotypes 1 and 2 show that resistance in plant introduction (PI) 200538 is not defeated by either SA biotype and thus this PI is a potential source of new, useful SA-resistance gene(s) (Kim et al. 2008). Recently, a new SA 
biotype was collected from the overwintering host glossy buckthorn (Frangula alnus) that can readily colonize plants with Rag2 (Hill et al. 2010). This has been named biotype 3 and it demonstrates the continued necessity to identity new SA-resistance genes and to stack the genes in soybean cultivars.

Several research groups have identified soybean genotypes with SA resistance and have mapped resistance genes onto soybean chromosomes. Hill et al. (2004a, b) first discovered nine SA-resistant genotypes. Of the nine genotypes, Dowling (PI 548663), Jackson (PI 548657), and 'Sugao Zarai' (PI 200538) were later shown as having SA resistance characterized as antibiosis by $\mathrm{Li}$ et al. (2004). Hill et al. (2006a, b) identified that a SA-resistance gene named Ragl was present in Dowling and a gene named Rag was present in Jackson. These were both dominant resistance genes and they were mapped to the same region between Satt463 and Satt435 on soybean chromosome 7 [linkage group (LG) M] (Li et al. 2007).

Mensah et al. (2008) identified two PIs with antibiosis resistance and two PIs with antixenosis resistance to SA. Zhang et al. (2009) further evaluated PI 567541B, one of the sources of antibiosis resistance, and mapped two recessive quantitative trait loci (QTL) from this source. They mapped one QTL onto chromosome 7 (LG M) and another onto chromosome 13 (LG F). The genetic location of the QTL on chromosome 7 was the same as the location of Ragl from Dowling, however, the QTL on chromosome 7 was recessive in contrast to the dominant resistance found for Ragl. They also identified a significant interaction between two genes (Zhang et al. 2009).

Mian et al. (2008a) identified that PI 243540, PI 567301B, and PI 567324 are resistant to SA biotype 2 collected in Ohio. Kang et al. (2008) showed that strong antibiosis resistance in PI 243540 was controlled by a single dominant gene that was mapped to chromosome 13 (LG F) by Mian et al. (2008b) and this gene was subsequently named Rag2. Hill et al. (2009) recently reported that PI 200538 carries a single dominant gene conferring resistance to both SA biotype 1 and 2 and this gene maps to the same genomic region as the Rag2 allele from PI 243540. Although it is not known whether the PI 200538 and PI 243540 resistance genes are allelic or are just tightly linked on chromosome 13, the PI 200538 gene will be referred to as Rag2 in this report.

Previous research mapped $R a g 2$ to a $10-\mathrm{cM}$ interval from PI 200538 and a 4.5-cM interval from PI 243540 (Hill et al. 2009; Mian et al. 2008b) resulting in large gaps between the gene and markers on these linkage maps. The objective of this study was to fine map the location of Rag2 from PI 200538 through the identification of additional genetic recombinants close to the gene and the development of single nucleotide polymorphism (SNP) markers by re-sequencing sequence-tagged sites (STSs) and target regions based on the Williams $828 \times$ draft assembly (Glyma1) (Schmutz et al. 2010). Fine mapping and highresolution linkage analysis of the region containing Rag2 will facilitate soybean aphid resistance breeding because SNP markers developed during this process that are closely linked to or within Rag2 can be used for marker-assisted selection (MAS). In addition, this research will aid efforts to clone Rag2 by positioning the gene into a small interval containing few candidate genes.

\section{Materials and methods}

\section{Plant material}

To fine map Rag2, three sources of soybean populations were used. The first was a population of $95 \mathrm{~F}_{2: 3}$ lines from the three-way cross LD02-4485 $\times($ Ina $\times$ PI 200538) that was originally used to genetically map Rag2 (Hill et al. 2009). The population was phenotyped for aphid resistance and genotyped with SSR markers in the $F_{2}$ and $F_{2: 3}$ generations as described by Hill et al. (2009). PI 200538 (Sugao Zairai) is a maturity group (MG) VIII soybean accession originating from Japan (USDA-ARS Germplasm Resources Information Network, http://www.ars-grin.gov/ npgs/; accessed 26 Oct 2009). Ina is a MG IV (relative maturity 4.5) soybean cyst nematode (SCN) (Heterodera glycines Ichinohe)-resistant cultivar that is susceptible to SA (Nickell et al. 1999; Hill et al. 2004a). LD02-4485 is a high yielding MG II experimental line developed by the University of Illinois that is SA susceptible and SCN resistant.

The second source of germplasm used in the Rag2 fine mapping was a set of $\mathrm{BC}_{2} \mathrm{~F}_{2: 3}, \mathrm{BC}_{3} \mathrm{~F}_{2: 3}$, and $\mathrm{F}_{2: 3}$ lines derived from plants selected for having putative genetic recombination in the interval containing Rag2 (Table 1). These were selected from a total of $3,151 \mathrm{BC}_{2} \mathrm{~F}_{2}, \mathrm{BC}_{3} \mathrm{~F}_{2}$, and $\mathrm{F}_{2}$ plants segregating for Rag2 that were grown in the field at Urbana, IL in 2008. These plants were screened with the SSR markers Satt510 and Satt114 (Song et al. 2004), which flanked the gene (Hill et al. 2009). One hundred and eighty-five plants with recombination events between the markers were selected and harvested. These selected recombinant lines were tested with three SNP markers (\#1485, \#20, and \#1) that map close to the Rag2 region to identify which lines have recombination events near the gene (Tables 2, 3; Fig. 1b). From the marker screening, 12 lines with recombination events in the marker intervals were identified and five were selected for SA resistance testing. Selected lines 18 and 32 are $\mathrm{BC}_{2} \mathrm{~F}_{2: 3}$ lines with the pedigree LD03-6566 (3) $\times$ [LD02-4485 $\times$ (Ina $\times$ PI 200538)] (Table 1). Line 86 is a $F_{2: 3}$ line with 
Table 1 Pedigree information for 243 recombinant lines identified during the fine mapping of Rag2 from PI 200538

\begin{tabular}{|c|c|c|c|}
\hline Line no. & No. of tested recombinant lines & Pedigree of lines & Generation of line \\
\hline $1-8$ & 8 & LD02-8782 × LD02-4485 (3) $\times($ Ina $\times$ PI 200538 $)$ & $\mathrm{F}_{2: 3}$ \\
\hline $9-36$ & 28 & LD03-6566 (3) $\times$ [LD02-4485 × (Ina $\times$ PI 200538) $]$ & $\mathrm{BC}_{2} \mathrm{~F}_{2: 3}$ \\
\hline $37-52$ & 16 & LD04-8782 $\times$ LD03-6566 $(2) \times[$ LD02-4485 $\times($ Ina $\times$ PI 200538) $]$ & $\mathrm{F}_{2: 3}$ \\
\hline $53-103$ & 51 & LD05-3230 × [LD02-4485 (3) $\times($ Ina $\times$ PI 200538) $]$ & $\mathrm{F}_{2: 3}$ \\
\hline 104-156 & 53 & LD05-3230 $\times$ LD03-6566 $(2) \times[$ LD02-4485 $\times($ Ina $\times$ PI 200538) $]$ & $\mathrm{F}_{2: 3}$ \\
\hline $157-185$ & 29 & LD02-4485 (4) × (Ina × PI 200538) & $\mathrm{BC}_{3} \mathrm{~F}_{2: 3}$ \\
\hline K1-K29 & 29 & LD03-6566 (4) $\times$ [LD02-4485 × (Ina $\times$ PI 200538) $]$ & $\mathrm{BC}_{3} \mathrm{~F}_{2: 3}$ \\
\hline K30-K48 & 19 & LD03-6566 × [LD02-4485 (4) $\times($ Ina $\times$ PI 200538) $]$ & $\mathrm{F}_{2: 3}$ \\
\hline K49-K58 & 10 & LD02-4485 (5) $\times($ Ina $\times$ PI 200538) & $\mathrm{BC}_{4} \mathrm{~F}_{2: 3}$ \\
\hline
\end{tabular}

the pedigree LD05-3230 $\times$ [LD02-4485 (3) $\times($ Ina $\times$ PI 200538)]. Lines 162 and 181 are $\mathrm{BC}_{3} \mathrm{~F}_{2: 3}$ lines that both have the pedigree LD02-4485 (4) $\times($ Ina $\times$ PI 200538). These last two lines were also tested with all SNP markers in the region except KS9-3 (Table 2). Both LD05-3230 and LD03-6566 are high yielding, SA susceptible experimental lines developed by the University of Illinois soybean breeding program.

The third source of germplasm was a set of 58 lines (K1-K58) selected for having putative genetic recombination in the interval containing Rag2 (Table 1) from a total of 2,632 $\mathrm{BC}_{3} \mathrm{~F}_{2}, \mathrm{~F}_{2}$, and $\mathrm{BC}_{4} \mathrm{~F}_{2}$ plants segregating for Rag 2 that were grown in the field at Urbana, IL in 2009. These plants were first screened with the SNP markers \#20 and \#1485, which flanked the gene (Table 2; Fig. 1b). Fifty-eight plants with recombination between the markers were selected and screened with SNP markers KS7 and KS12 to identify which plants had recombination events close to the gene (Table 2). From the marker screening, three plants with recombination events between KS7 and KS12 were identified, and lines were derived from the three plants and used in progeny tests. Selected line $\mathrm{K} 16$ is a $\mathrm{BC}_{3} \mathrm{~F}_{2: 3}$ line with the pedigree LD03$6566(4) \times[$ LD02-4485 × (Ina $\times$ PI 200538)]. Lines K31 and $\mathrm{K} 37$ are in the $\mathrm{F}_{2: 3}$ generation and have the pedigree LD03-6566 × [LD02-4485 (4) $\times($ Ina $\times$ PI 200538) $]$. Progeny plants from the three recombinant lines were tested with all SNP markers.

\section{Aphid culture}

The SA biotype 2 was established at the Ohio Agricultural Research and Development Center (OARDC), Wooster, Ohio during the summer of 2005 by collecting aphids from nearby soybean fields. Biotype 2 was maintained on a continuous supply of plants of LD05-16611, an experimental line developed by the University of Illinois, which has Ragl from Dowling. The SAs were maintained in a growth chamber at $22^{\circ} \mathrm{C}$ and under 16 -h irradiation and $70 \%$ relative humidity (Hill et al. 2004a).
Soybean aphid biotype 2 resistance evaluation

The $95 \quad \mathrm{~F}_{2: 3}$ lines from the LD02-4485 $\times($ Ina $\times$ PI 200538) population were tested for resistance to SA biotype 2 as described by Hill et al. (2009). Briefly, a minimum of $11 \mathrm{~F}_{3}$ plants from each line were tested with SA biotype 2 in a greenhouse and rated for aphid colonization on a 1-4 scale with $1=$ few solitary live aphids and $4=$ dense colonies accompanied by plant damage. The greenhouse was maintained at $22-25^{\circ} \mathrm{C}$ with $14 \mathrm{~h}$ ambient light supplemented by $1,000-\mathrm{W}$ high pressure sodium vapor lamps positioned approximately $2 \mathrm{~m}$ above the greenhouse benches (Hill et al. 2004a).

Progeny from the eight selected recombinant plants were tested for SA resistance using choice tests with biotype 2 in order to determine the position of the Rag 2 gene relative to the recombination points in each line. Lines 18 and 32 were the first evaluated for resistance. This was followed by testing lines 86,162 , and 181 , followed by testing of K16, K31, and K37. These tests included from 38 to 67 progeny plants from each selected recombinant line (Table 2). In all SA resistance tests, the photoperiod was $14 \mathrm{~h}$ and the temperature was between 22 and $25^{\circ} \mathrm{C}$. The first SA resistance test was conducted in a plant growth chamber with $30 \mu \mathrm{mol} \mathrm{m} \mathrm{m}^{-2} \mathrm{~s}^{-1}$ photosynthetically active radiation (PAR) (Kim et al. 2008). The second SA resistance test was conducted in plant growth chamber with $300 \mu \mathrm{mol} \mathrm{m}{ }^{-2} \mathrm{~s}^{-1}$ PAR. The third SA resistance test was conducted in a greenhouse under conditions described above.

Individual plants were grown in 60 by 60 by $60-\mathrm{mm}$ plastic 48-pot inserts (Hummert Intl., Earth city, MO, USA) contained inside plastic trays without holes (Hummert Intl.) as described by Kim et al. (2008). Each 48-pot insert included 44 progeny from a line and two replications of the parents PI 200538 and LD02-4485. The 48 plants in an insert were arranged in a completely randomized design. Experiments were inoculated by placing leaves of LD05-16611 that were infested with 


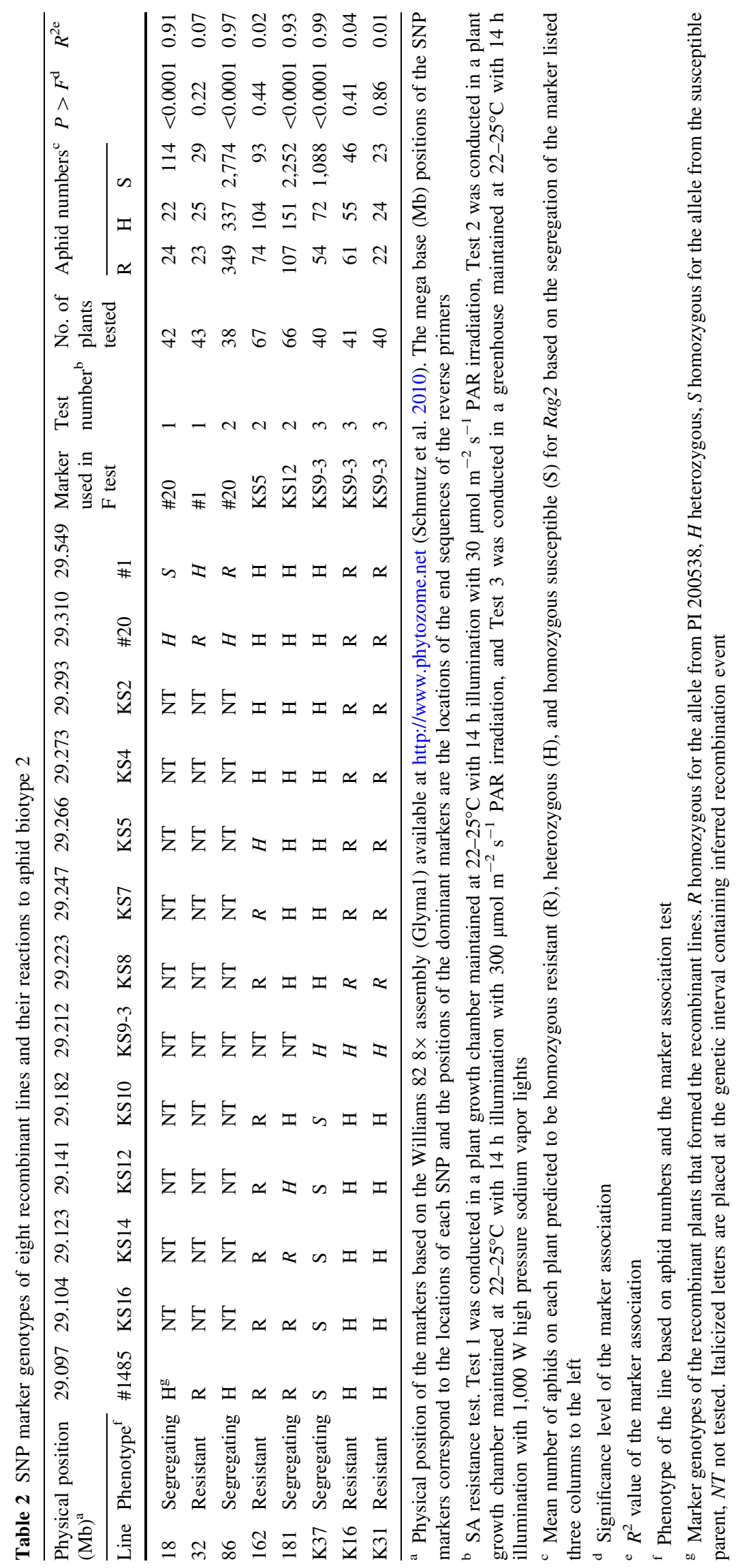


Table 3 Information on the 35 STSs on chromosome 13 (LG F) (Hyten et al. 2010) that were sequenced during the fine mapping of Rag2

\begin{tabular}{|c|c|c|c|}
\hline Marker name & $\begin{array}{l}\text { GenBank } \\
\text { accession \# of STS }\end{array}$ & $\begin{array}{l}\text { NCBI-dbSNP name of } \\
\text { SNP located on STS }\end{array}$ & $\begin{array}{l}\text { Consensus Map } 4.0 \\
\text { Position (cM) }\end{array}$ \\
\hline \#1 & GF097646 & ss4969612 & 52.261 \\
\hline \#2 & GF097659 & ss4969648 & 49.924 \\
\hline \#3 & GF097679 & ss4969734 & 50.395 \\
\hline \#4 & GF091828 & ss 107912850 & 51.666 \\
\hline \#5 & GF091836 & ss 107914023 & 51.936 \\
\hline \#6 & GF091900 & ss 107912922 & 55.317 \\
\hline \#7 & GF091960 & ss107912982 & 55.858 \\
\hline \#8 & GF092024 & ss 107913046 & 56.031 \\
\hline \#9 & GF092100 & ss 107913125 & 50.103 \\
\hline \#10 & GF092140 & ss 107913165 & 54.149 \\
\hline \#11 & GF092174 & ss107913199 & 56.171 \\
\hline \#12 & GF092326 & ss 107913351 & 52.389 \\
\hline \#13 & GF093742 & ss 107917482 & 48.349 \\
\hline \#14 & GF092414 & ss 107913443 & 49.424 \\
\hline \#15 & GF092564 & ss107913594 & 56.94 \\
\hline \#16 & GF092576 & ss107918675 & 52.338 \\
\hline$\# 17$ & GF097352 & ss 107912576 & 54.374 \\
\hline$\# 18$ & GF093970 & ss 107918696 & 49.932 \\
\hline \#19 & GF092628 & ss 107913658 & 54.078 \\
\hline$\# 20$ & GF094005 & ss 107918836 & 56.609 \\
\hline \#21 & GF092655 & ss 107913685 & 51.598 \\
\hline \#22 & GF097432 & ss 107912657 & 53.202 \\
\hline$\# 23$ & GF097440 & ss 107912665 & 54.922 \\
\hline$\# 24$ & GF094366 & ss 107920248 & 49.32 \\
\hline$\# 25$ & GF094412 & ss 107920435 & 55.989 \\
\hline \#26 & GF094471 & ss 107920639 & 56.243 \\
\hline \#27 & GF097393 & ss 107912618 & 53.202 \\
\hline \#28 & GF094141 & ss 107919283 & 51.602 \\
\hline \#29 & GF094142 & ss 107919284 & 50.707 \\
\hline \#30 & GF094701 & ss 107921354 & 54.078 \\
\hline \#31 & GF096278 & ss 107927651 & 55.781 \\
\hline \#32 & GF096883 & ss 107929664 & 53.202 \\
\hline \#33 & GF096992 & ss107929998 & 52.218 \\
\hline \#34 & GF097147 & ss 107930597 & 51.896 \\
\hline \#1485 & GF097621 & ss 4969627 & NA \\
\hline
\end{tabular}

200-300 aphids of biotype 2 at all life stages on top of $\mathrm{V}_{\mathrm{E}}$-stage seedlings. Ten days after inoculation, resistance was evaluated by counting the total number of aphids on each plant.

\section{DNA extraction}

Genomic DNA from the $95 \mathrm{~F}_{2}$ plants was extracted using young trifoliolate leaves of each plant with the CTAB (hexadecylatrimethylammonium bromide) method described by Honeycutt et al. (1992) with minor modifications (Hill et al. 2009). Because tissue samples were collected during the SA resistance evaluation experiment, aphids were eliminated from leaves with the systemic insecticide imidacloprid prior to sampling.

Genomic DNA from the $3,151 \mathrm{BC}_{3} \mathrm{~F}_{2}, \mathrm{BC}_{2} \mathrm{~F}_{2}$, and $\mathrm{F}_{2}$ plants in 2008 and 2,632 $\mathrm{BC}_{3} \mathrm{~F}_{2}, \mathrm{~F}_{2}$, and $\mathrm{BC}_{4} \mathrm{~F}_{2}$ plants in 2009 was extracted using young trifoliolate leaf tissue from each plant using the quick extraction method (Bell-Johnson et al. 1998). Genomic DNA from 185 recombinant lines selected in 2008 and 58 recombinant plants selected in 2009 was extracted using young trifoliolate leaf tissue pooled from 12 progeny plants from each line using the CTAB method described above.

After the completion of the resistance assays, genomic DNA from each of the 377 individual progeny from the 


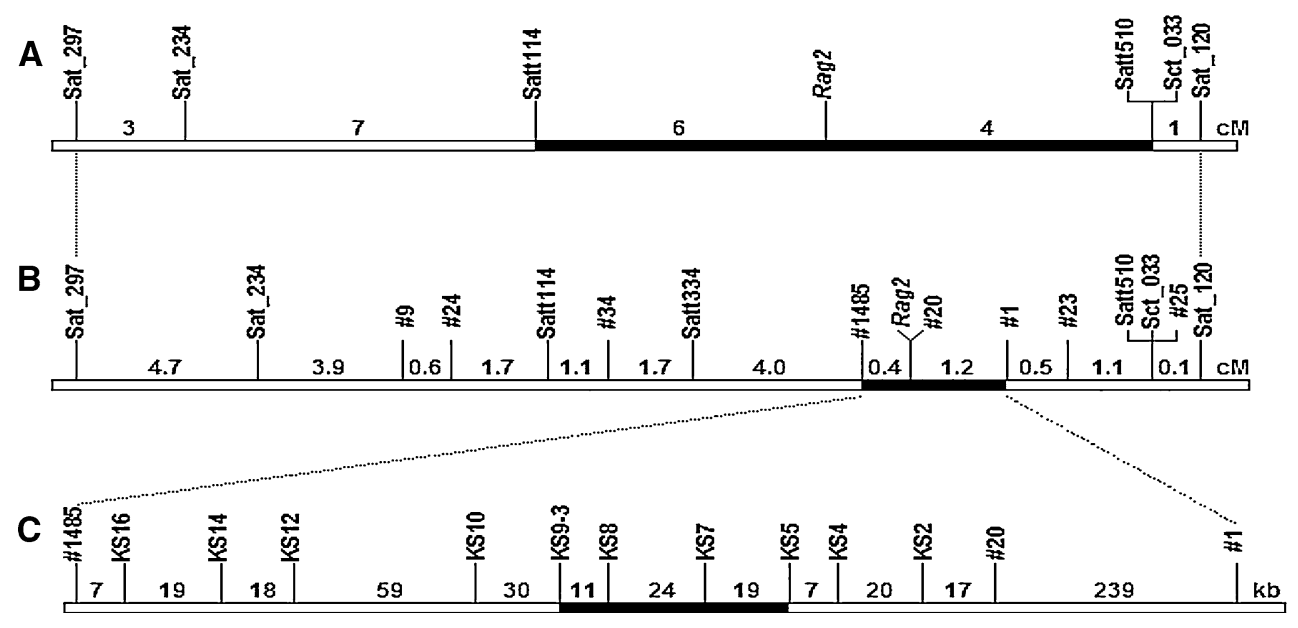

Fig. 1 Genetic and physical maps of the interval Rag2 is located on soybean chromosome 13 (LG F). a Linkage map of the interval Rag2 is located using the same population of $95 \mathrm{~F}_{2: 3}$ lines as Hill et al. (2009). The numbers between the markers are the linkage distances in centiMorgans (cM). b Linkage map of the interval Rag2 is located using SNP markers developed by re-sequencing of STSs using the same Hill et al. (2009) population. c High-resolution physical map of

eight selected recombinant lines in these assays was extracted using the CTAB method. All CTAB DNA was quantified by ND-1000 Spectrophotometer (NanoDrop Technologies, Wilmington, DE, USA) and diluted to $25 \mathrm{ng} \mu \mathrm{l}^{-1}$ for SSR genotyping and $20 \mathrm{ng} \mu \mathrm{l}^{-1}$ for SNP genotyping.

SSR marker re-screening within the interval containing $\operatorname{Rag} 2$

All SSR markers previously mapped between Satt510 and Satt114 on chromosome 13 (LG F) were retested to determine if any were polymorphic between PI 200538 and LD02-4485, the two parents of the first mapping population that includes $95 \mathrm{~F}_{2: 3}$ lines. The primer sequences and location of the SSR markers are available from Soybean Linkage Map-2006 (http://bfgl.anri.barc.usda.gov/cgi-bin/ soybean/Linkage.pl; accessed 27 May 2009). Polymerase chain reaction (PCR) was performed according to Cregan and Quigley (1997). PCR reactions consisted of 36 cycles of denaturation at $94^{\circ} \mathrm{C}$ for $25 \mathrm{~s}$, annealing at $46^{\circ} \mathrm{C}$ for $25 \mathrm{~s}$, and extension at $68^{\circ} \mathrm{C}$ for $25 \mathrm{~s}$ with a PTC 100 Programmable Thermal Controller (MJ Research Inc., Watertown, MA, USA) with slight modifications according to the specific annealing temperature of the primers. The PCR products were first analyzed in $3 \%$ agarose gels (BMA, Rockland, ME, USA) and then retested in $3 \%$ metaphor-agarose gels with ethidium bromide staining in $1 \times$ Tris-Borate-EDTA buffer. the interval Rag2 is located using eight recombinant lines and SNP markers developed by re-sequencing in the target interval. Numbers between the markers show physical distances in kilo bases $(\mathrm{kb})$ on the Williams $828 \times$ assembly (Glyma1) available at http://www. phytozome.net (Schmutz et al. 2010). The interval containing Rag2 was narrowed down to a 54-kb region between the markers KS9-3 and KS5

Re-sequencing of STSs

To develop additional markers and narrow the gene interval, re-sequencing of STSs already mapped to the region on soybean chromosome 13 (LG F) where Rag2 is located was performed. Information on target amplification primer pairs for the 34 STSs (Table 3) containing SNPs from this region was obtained from Hyten et al. (2010). These STSs were first re-sequenced to determine if the SNPs previously identified were present between the parents of the recombinant lines. A target amplification primer pair for one additional STS, GF097621 (Table 3), was designed using IDT SciTools PrimerQuest ${ }^{\mathrm{SM}}$ software (Integrated DNA Technologies, Coralville, IA, USA).

The re-sequencing was done by first PCR amplifying the STSs. Amplification reactions were conducted with $100 \mathrm{ng}$ of parental DNA, $0.25 \mu \mathrm{M}$ of forward and reverse primer, $1 \times$ of buffer (BioLabs Inc., MA, USA), $0.25 \mathrm{mM}$ of each dNTP (Applied Biosystems, Foster City, CA, USA), and $1 \mathrm{U}$ of Taq polymerase (BioLabs Inc.), in a total volume of $40 \mu \mathrm{l}$. The reaction mixture was denatured at $95^{\circ} \mathrm{C}$ for $1 \mathrm{~min}$ and subjected to 28 cycles of $94^{\circ} \mathrm{C}$ for $30 \mathrm{~s}$, annealing at $55^{\circ} \mathrm{C}$ for $40 \mathrm{~s}$, and extension at $68^{\circ} \mathrm{C}$ for $2 \mathrm{~min}$ $20 \mathrm{~s}$, followed by one cycle of $8 \mathrm{~min}$ at $68^{\circ} \mathrm{C}$ using a PTC 100 Programmable Thermal Controller (MJ Research Inc.). PCR products were resolved by gel electrophoresis in $0.9 \%$ TAE agarose gels stained with ethidium bromide. The presence of a single PCR product was verified for each primer pair. If primer pairs produce no product or multiple 
products, annealing temperatures or PCR cycles were modified to identify the optimum PCR condition for each primer pair (Choi et al. 2007).

When single PCR products from the two parents were produced, these were purified with the QIAquick Gel Extraction Kit (Qiagen, CA, USA). Purified PCR products were then sequenced from both ends using the same primers as for PCR amplification with the ABI BigDye Terminator v3.1 cycle sequencing kit on an ABI PRISM 3730 sequencer (Applied Biosystems) at the University of Illinois Keck Center Core Facility. To detect SNPs between two parents, ABI trace files were analyzed by Sequencher version 4.9 (Gene Codes Corporation, Ann Arbor, MI, USA).

Saturation of the Rag2 region with additional SNP markers

Once Rag2 was positioned relative to the SNPs developed from the STSs, direct re-sequencing of target regions was conducted to develop additional SNP markers that could be used to better define the genomic position of Rag2. A total of 27 target amplification primer pairs were designed every $10 \mathrm{~kb}$ between nucleotides 29,097 and $29,310 \mathrm{~kb}$ on chromosome 13 based on the Williams $828 \times$ draft assembly (Glyma1) (Schmutz et al. 2010). The primers were designed with IDT SciTools PrimerQuest ${ }^{\text {SM }}$ software (Integrated DNA Technologies). The uniqueness of each primer pair in the genome was double-checked by BLAST analysis. Sequencing and SNP detection were conducted as described above.

\section{SNP marker and dominant marker genotyping}

Target amplification primers and probes for TaqMan assays or melting curve assays (MCAs) were designed for the confirmed SNPs. Target amplification primers and simple probe for MCA were designed by use of the LightCycler ${ }^{\circledR}$ Probe Design Software 2.0 (Roche Diagnostics, Switzerland) and were blasted to Williams $828 \times$ draft assembly (Glyma1) to check whether there was a single match of the sequences and to verify their position in the soybean genome. If a target amplification primer or simple probe matched multiple regions of the soybean genome, the primer or probe was redesigned until it had a single match in the soybean genome. TaqMan primers and probes were designed by Assays-by-Design Service (Applied Biosystems). SNP marker genotyping using TaqMan assays or MCAs was conducted with the Roche LightCycler ${ }^{\circledR} 480$ System (Roche Diagnostics, Indianapolis, IN, USA) described by Kaczorowski et al. (2008).

The target sequencing primer pairs KS8 and KS10 produced a desired single PCR product only for the susceptible parent LD02-4485 and were used as dominant markers. These markers could distinguish homozygous resistance alleles from homozygous susceptible alleles, but could not distinguish homozygous susceptible alleles from heterozygous alleles. Therefore, plants having no PCR product were classified as homozygous resistance and those with a product were classified as heterozygous or homozygous susceptible. The forward and reverse primer sequences of KS8 were 5'-TACCCTCAAATGGACTTGGTGCCT-3' and $5^{\prime}$-TGGCGATGGTGATCTTGACTGTCT-3', receptively. The forward and reverse primer sequences of KS10 were $5^{\prime}$-TCCCATTACGCCGTTCAGCAAGAT- $3^{\prime}$ and 5'-GGTGTACAAGGAAAGCCCAAGACT-3'. PCR condition for these two markers was the same as for the SSR marker and the PCR products were analyzed in $1 \%$ agarose gels. All markers for lines with genotypes given on Table 2 were tested on each progeny plant in the aphid assays resulting in 3-13 markers tested on these progeny plants.

Genetic mapping and statistical analysis

Molecular marker and phenotype data were used to construct a genetic map with the $95 \mathrm{~F}_{2: 3}$ lines from the LD02$4485 \times($ Ina $\times$ PI 200538$)$ population. Linkage analysis was performed with JoinMap 3.0 (Van Ooijen and Voorrips 2001) using the Kosambi mapping function. A logarithm (base 10) of the odds (LOD) score of 5.0 was used as a threshold to group markers into a linkage group.

To test whether Rag2 was segregating among plants in each of the eight recombinant lines phenotyped for SA resistance, the progeny plants that had been evaluated for SA resistance were tested with a polymorphic marker in each line that maps near Rag2. Single factor analysis of variance was used to identify the associations between SA resistance and marker segregation using the PROC GLM procedure of SAS (SAS Institute 2002).

\section{Results}

Genetic mapping of Rag2 using SSR markers and SNP markers developed by STS re-sequencing

The retesting of all SSR markers mapped between Satt114 and Satt510 on chromosome 13 (LG F) revealed that Satt334 was polymorphic between PI 200538 and LD024485. The polymorphism between the two soybean genotypes could not be distinguished in 3\% agarose gels, so this marker was genotyped with 3\% metaphor-agarose gels. Satt334 is located between Satt114 and Satt510 on the genetic map developed by Hill et al. (2009) (Fig. 1a, b).

STSs previously mapped near the Rag2 locus were re-sequenced to saturate the SSR map and to further 
define the location of Rag2 on chromosome 13. Thirtyfour out of the 35 STSs producing a single PCR product in both parents and were sequenced (Table 3). STS \#28 was the exception and failed to produce an amplification product. Sixteen of the STSs were found to have 29 SNPs and 33 small insertion/deletions (INDELs). Among these 16 STSs, 8 (\#1, \#9, \#20, \#23, \#24, \#25, \#34, \#1485) contained SNPs that were appropriate for the development of MCA or TaqMan SNP marker assays (Tables 4, 5).

The eight SNP markers developed from re-sequencing the STSs were incorporated onto the genetic map developed by Hill et al. (2009). All SNP markers were mapped between Satt510 and Sat_234. Rag2 was mapped between the SNP markers \#1 and \#1485 and co-segregated with SNP \#20 (Fig. 1b). This resulted in narrowing the genetic interval containing the gene from 10 to $1.6 \mathrm{cM}$ in length using the $95 \mathrm{~F}_{2: 3}$ lines from the LD02-4485 $\times($ Ina $\times$ PI 200538) population (Fig. 1a, b).

Fine mapping of Rag2 using SNP markers developed by re-sequencing

To further define the position of Rag2, SNP marker analyses and SA resistance tests were conducted on progeny plants from the five lines $(18,32,86,162$, and 181) identified in 2008 as having recombination events between SNP markers \#1 and \#20 or \#20 and \#1485. The lines 18, 32, and 86 had recombination events between \#20 and \#1. The SA resistance segregation among plants in the progeny tests were consistent with the segregation of \#20 and $\# 1485$, but not \#1, suggesting that Rag2 is likely between \#20 and \#1485 (Table 2).

Direct re-sequencing in the interval between \#20 and \#1485 was then done to identify additional SNPs that could be used to refine the map position of Rag2. Although one target amplification primer pair was designed for each $10 \mathrm{~kb}$ within the interval, some regions did not have sufficient sequence information suitable to design target amplification primers as a result of the draft quality of the soybean genome at the time. A total of 27 primer pairs were designed with thirteen of the 27 primer pairs producing a single PCR product for both parents. Through sequencing of the PCR products from both parents, SNP markers were developed for seven primer pairs. In addition, the two primer pairs KS8 and KS10 produced a single PCR product from only LD02-4485 DNA and failed to amplify a product from PI 200538 and were used as a dominant marker in genotyping the recombinant lines. By testing all progeny plants from the greenhouse resistance evaluations with these dominant markers, lines derived from heterozygous and homozygous susceptible plants could be distinguished (Table 2).
Individual plants from the lines 162 and 181, which were identified as having recombination between SNP markers \#20 and \#1485, were genotyped with the nine new markers (Table 2). Line 162 was segregating for SNP markers from KS5 to \#1 alleles and homozygous resistant from KS7 to \#1485. No significant association between the segregation of aphid resistance and the SNP marker KS5 was observed for this line (Table 2) and all tested plants had a resistant phenotype. The results for line 162 show that Rag2 must be to the left of KS5 in the genetic map. The left border of the position of Rag2 was refined by analysis of line 181. This line was segregating for SNP markers from KS12 to \#1 and homozygous resistant for markers from \#1485 to KS14. There was a highly significant association $(P<0.0001)$ between aphid resistance and the segregation of the SNP marker KS12 in the line (Table 2), showing that Rag2 was segregating and therefore to the right of KS14. A BLAST analysis indicated that the SNP detected by the marker KS5 is located at $29,266,469$ bp and the SNP detected by the marker KS14 is located at 29,123,397 bp on chromosome 13. Therefore, the genomic region containing the gene was narrowed to an interval approximately $143 \mathrm{~kb}$ in length (Table 2; Fig. 1c) based on the Williams 82 sequence.

To further refine the position of Rag2 within the 143-kb region, re-sequencing was done to identify additional DNA markers within the region. Nine target amplification primer pairs were designed for re-sequencing between KS7 and KS12. Of the nine primer pairs, three did not produce a PCR product from PI 200538 and two did not produce a PCR product from both parents. This poor success rate was likely the result of low sequence homology between the Williams 82 sequence, which was used to design the primers, and LD00-4485 and PI 200538, the parent used to test the primers. Four primer pairs produced products from both parents and these products were sequenced. The sequences of three products contained too many SNPs and INDELs which made it impossible to develop SNP assays. A SNP assay was successfully developed from only the remaining SNP marker (KS9-3).

A total of $2,632 \mathrm{BC}_{3} \mathrm{~F}_{2}, \mathrm{~F}_{2}$, and $\mathrm{BC}_{4} \mathrm{~F}_{2}$ plants grown in the field at Urbana, IL in 2009 were tested with the markers KS7 and KS12 to find additional recombination events within the interval. Three plants were identified with recombinations in the interval and the lines $\mathrm{K} 16, \mathrm{~K} 31$, and K37 were derived from these recombinant plants. Progeny plants from these lines were genotyped with all SNP markers and tested for SA resistance. The line K37 was segregating for SNP markers from KS9-3 to \#1 and was fixed for markers \#1485 to KS10. There was a highly significant $(P<0.0001)$ association between these segregating SNP markers and SA resistance, indicating that Rag2 was to the right of KS10 (Table 2). Lines KS16 and 
Table 4 Sequences of target amplification primers and MCA sensor probes used for SNP genotyping

\begin{tabular}{|c|c|c|}
\hline Marker name & Type & Sequences \\
\hline \multirow[t]{3}{*}{$\# 1$} & Forward & CTCGAAAGGTGAACATGCACCA \\
\hline & Reverse & AGAACATTAAGAGATATGGGAAGGAAGTAG \\
\hline & Probe & Fluorescein-SPC-TTAATACACATATAAATTTTGAGAGCATTTAAGT-Phosphate \\
\hline \multirow[t]{3}{*}{ \#9 } & Forward & CAAACCAACCAAATGCTCAGAATACACG \\
\hline & Reverse & AATGAATAATTCATATGATTAATAGG \\
\hline & Probe & Fluorescein-SPC-AGTGCATGCATACCTTTAGTTGCTGGATTTGAGAT-Phosphate \\
\hline \multirow[t]{3}{*}{ \#20 } & Forward & ACATTGCAATCAAAATCAAGATGTAGCTGG \\
\hline & Reverse & GACGATTTTGGTTTCTGTGATCTTACGTG \\
\hline & Probe & Fluorescein-SPC-TTCTGTAGCTTCTACCCAAGGGCTAGCCTTATCCA-Phosphate \\
\hline \multirow[t]{3}{*}{ \#23 } & Forward & ATGCCAATCCATTCTAAAGT \\
\hline & Reverse & GGATCATTGATGGCACGA \\
\hline & Probe & Fluorescein-SPC-TTCTGCAAACATAAACGGATCAAAATATCA-Phosphate \\
\hline \multirow[t]{3}{*}{ \#24 } & Forward & CCCCATGGAAATTAAGATTCCTGC \\
\hline & Reverse & GCATGAGCACAAAGTTTTTCTTGGC \\
\hline & Probe & Fluorescein-SPC-ATGCCCATGGTTAATTAAGTAAACACATTT-Phosphate \\
\hline \multirow[t]{3}{*}{ \#25 } & Forward & GTGTGCATGTGTTTGAACTTTGAAGAGATT \\
\hline & Reverse & ATCACAGAGACATGGAGGTTGCTAT \\
\hline & Probe & Fluorescein-SPC-CTTGTCCTCCTGACTCTCTCCAGGTACTT-Phosphate \\
\hline \multirow[t]{3}{*}{ \#34 } & Forward & AGAATATTATGAAGATCAAACATGAACAA \\
\hline & Reverse & AATAATGTTTTGTTTAATACTTTTACTTGG \\
\hline & Probe & Fluorescein-SPC-TTTCTCCTTTAAAAATAAGTAGAACCATTTTTTT-Phosphate \\
\hline \multirow[t]{3}{*}{$\mathrm{KS} 2$} & Forward & CTGCATCAGCTACTTCATGAGGAG \\
\hline & Reverse & GGTCTGATTTGCTATTAAACCATCTTCCTT \\
\hline & Probe & Fluorescein-SPC-ACCAGTCCTCTGAAAAAGTGAAGAGAAATCAACAA-Phosphate \\
\hline \multirow[t]{3}{*}{ KS4 } & Forward & ACCACAAAACAAGCAAATGAGTCACT \\
\hline & Reverse & GTGCATGTTCGTTGTGATTTTCCCT \\
\hline & Probe & Fluorescein-SPC-CAATGCACAAGTAGGAAAAATCATCCAAACGGGAA-Phosphate \\
\hline \multirow[t]{3}{*}{ KS5 } & Forward & CATGGAAGGCTGATAATACAGACATGTACC \\
\hline & Reverse & CGTCGAGCTTAATGCGTGAAGGAAA \\
\hline & Probe & Fluorescein-SPC-GGAAGAGGATGAGGACGCCATCATCGACATTCA-Phosphate \\
\hline \multirow[t]{3}{*}{ KS7 } & Forward & CAGGGCAAAGTGTGGAGACAAT \\
\hline & Reverse & CAATCCATTATACGCTATACACTCCCCTTC \\
\hline & Probe & Fluorescein-SPC-AGCTAGTTCGATTTTATCAACAATTAGGGTGATGA-Phosphate \\
\hline \multirow[t]{3}{*}{ KS12 } & Forward & ATCAAGCTCACTCCTTATTGAATAAACCT \\
\hline & Reverse & ACATTGATCCATTATGTTTGCTTAACAAGT \\
\hline & Probe & Fluorescein-SPC-AAAGGAATGCATTAGAAACTTATTGCCACTCCTCA-Phosphate \\
\hline \multirow[t]{3}{*}{ KS14 } & Forward & CTTCCGTCATCCATTAAGAGCAATTCATTT \\
\hline & Reverse & TGGATGCAGAGGTTGTGTATGTGGTTTAG \\
\hline & Probe & Fluorescein-SPC-AGTTGTTAACATGACAAGAGGTGAAAGAGACGAGT-Phosphate \\
\hline \multirow[t]{3}{*}{ KS16 } & Forward & CAGGTTCTTCACTCAAGTTGTTGCT \\
\hline & Reverse & AATCAGAATCAGATTGAAAACAAGACACCA \\
\hline & Probe & Fluorescein-SPC-GTCACATTTTGTTTTTGTTGTAATTTTGTTGGA-Phosphate \\
\hline
\end{tabular}

KS31 were segregating for SNP marker alleles from \#1485 to KS9-3 and homozygous resistant from KS8 to \#1. Because there was no significant association between aphid resistance and segregation for the SNP marker KS9-3 for these lines, Rag2 must be to the right of KS9-3. A BLAST analysis revealed that the SNP marker KS9-3 was located at $29,212,318 \mathrm{bp}$ on soybean chromosome 13 (LG F). These results indicated that Rag2 maps within a $54-\mathrm{kb}$ region defined by KS9-3 and KS5 on soybean chromosome 13 (Table 2; Fig. 1c). 
Table 5 Sequences of target amplification primers and TaqMan probes for SNP genotyping

\begin{tabular}{lll}
\hline Marker name & Type & Sequence \\
\hline$\# 1$ & Forward & AGAACATTAAGAGATATGGGAAGGAAGTAGT \\
& Reverse & GGAACATTACTAAAAACGATATGTCAAAGTTAGAA \\
& Probe 1 & ATTTTGAGAGCATTTAAG-VIC \\
& Probe 2 & AATTTTGAGAGCTTTTAAG-FAM \\
$\# 20$ & Forward & AAATCAAGATGTAGCTGGATGGATAAGG \\
& Reverse & GCTTTTGCACTTGAATTATTTGTTTTCTGT \\
& Probe 1 & CCCTTGGGTAGAAGC-VIC \\
& Probe 2 & CCCTTGGATAGAAGC-FAM \\
Forward & GCATAGAAATTTACACATCCATCAACCAT \\
& Reverse & CGTTTGGGAATAGCTTACAAGCTT \\
& Probe 1 & ACTCTACCCTGACAATAG-VIC \\
Probe 2 & CTCTACCCTCACAATAG-FAM \\
FS9-3 & Forward & ACGTCAAGTGATGACTTAACACTTGT \\
& Reverse & AGAAGTAGGAAGGACAAAACTTGAATATAAAGAAAAA \\
& Probe 1 & ATCATTAGAAAACGAAATAA-VIC \\
& Probe 2 & ATCATTAGAAAACAAAATAA-FAM \\
\hline
\end{tabular}

\section{Discussion}

The SA-resistance gene Rag2 from PI 200538 was fine mapped in this study. Mian et al. (2008b) also mapped a single dominant gene named Rag2 from PI 243540 to the same region on soybean chromosome 13 (LG F). Because these genes map to the same region and they both show resistance to SA biotype 2, it is likely that both sources have a resistance allele at the Rag2 locus.

Our mapping efforts were greatly accelerated by the availability of the public sequence of the soybean genome (Schmutz et al. 2010). This sequence information was especially valuable in discovering SNPs through direct re-sequencing of target regions, determining the position of markers on the physical map, and identifying candidate genes in the region where the gene is located.

The current gene annotation of the 54-kb region containing the Rag2 locus on the aphid susceptible Williams 82 $8 \times$ assembly (Glyma1) predicts the presence of seven candidate genes. Of these genes, Glyma13g26000 is the only nucleotide-binding site (NBS)-leucine-rich repeat (LRR) candidate gene and is therefore the strongest Rag2 candidate based on the Williams 82 sequence. Glyma13g26000 encodes a F-Box/LRR protein and shares significant homology with Arabidopsis and soybean sequences encoding disease resistance proteins such as the coiled-coil (CC)-NBS-LRR or toll-interleukin receptor-NBS-LRR classes of genes. Wang et al. (2005) demonstrated that the soybean F-box protein gene GmCOII mediates Jasmonate (JA) that regulates plant defense and fertility in Arabidopsis. Li et al. (2008) suggested that JA-, ethylene-, and salicylic acid (SA)-regulated signaling pathways were at least partially activated by aphid feeding on soybean.
The majority of cloned resistance genes are members of the NBS-LRR gene family. Cloned NBS-LRR genes that confer aphid resistance include the $M i$ gene, which controls root-knot nematode (Meloidogyne incognita) and potato aphid (Macrosiphum euphorbiae) resistance in tomato (Lycopersion esculentum Mill.) (Milligan et al. 1998; Rossi et al. 1998), and the Vat gene, which confers resistance to A. gossypii in melon (Cucumis melo L.) (Brotman et al. 2002; Dogimont et al. 2009). In addition, an aphid-resistance gene in Medicago truncatula Gaertner was mapped to a NBS-LRR cluster region (Klingler et al. 2005).

A prominent aspect of the genome organization of the NBS-LRR gene family is that members tend to occur in localized clusters (Martin et al. 2003). Such clustering is seen both for resistance genes specific for different races of the same pathogen (Hulbert and Bennetzen 1991) and for resistance genes conferring resistance to unrelated pathogens (Witsenboer et al. 1995). For instance, three NBSLRR genes were interspersed in a 213-kb region at the Mla locus in barley, which controls resistance to multiple strains of powdery mildew (Wei et al. 1999). In the 84-kb region between KS10 and KS5, where Rag2 is located, three NBS-LRR genes are present. These include Glyma13g26000, our best candidate for Rag2, the Rpg1-b gene, which confers resistance to Pseudomonas syringae pv. glycine (Ashfield et al. 2003), and a third NBS-LRR candidate gene of unknown function. Both Rpgl-b and the third gene are outside the 54-kb region containing Rag2, so they are likely not Rag2. Our research on fine mapping Ragl also showed that the $115-\mathrm{kb}$ region including Ragl contains two NBS-LRR genes (Kim et al. 2010). These gene predictions for the Rag2 region are all based on the Williams 82 sequence and Williams 82 does not contain 
the resistance allele at $\operatorname{Rag} 2$. The region containing Rag2 will need to be cloned from PI 200538 and sequenced to determine whether these same predicted genes exist in PI 200538.

A major peanut root-knot nematode [M. arenaria (Neal) Chitwood]-resistant QTL was previously mapped to the same region as Rag2 on soybean chromosome 13 using PI 200538 as a resistance source (Tamulonis et al. 1997). The mapping of both aphid and nematode resistance to the same region on chromosome 13 from PI 200538 suggests that Rag2 could be analogous to the $M i$ gene in conferring resistance to both aphids and nematodes. Further work is needed to determine whether peanut root-knot nematode resistance maps to the same position as Rag2.

Tamulonis et al. (1997) also mapped a minor peanut root-knot nematode-resistance QTL to chromosome 15 (LG E) and there is evidence of homology between the Rag2 region and the region on chromosome 15 that contains this minor QTL. This homology is shown by the STS GF097621, which was used to develop the SNP marker\#1485. When the SNP was developed through re-sequencing, the STS was located on soybean chromosome 13 in SoyBase (http://soybase.org/) and the Williams $828 \times$ draft assembly (Glyma1) (verified Feb 2009), and its assembly sequence was perfectly matched to chromosome 13 and partly (85\%) matched chromosome 15 (LG E). SNP marker \#1485 also was mapped on soybean chromosome 13 through linkage analysis in our research when we used LOD score 5.0 or higher in JoinMap 3.0. At present, however, the location of the STS has been repositioned to between 4,130,5182-4,130,5716 bp onto chromosome 15 in SoyBase (http://soybase.org/) and Phytozome (http:// www.phytozome.net), which is between the SSR markers Satt491 and Satt685 (1,966,3839-4,827,3769 bp). This is the same interval that Tamulonis et al. (1997) mapped the minor peanut root-knot nematode QTL from PI 200538 (GmComposite 2003, http://soybase.org/) indicating regions that include the STS on chromosome 13 and 15 have high homology or are duplicated. This homology is supported by Shoemaker et al. (1996) who reported that an extensive region of homology on soybean chromosomes 13 and 15 exist. Hayes et al. (2000) also reported that two NBS-LRR classes of disease-resistance genes identified by the same probe were mapped on soybean chromosome 13 and 15 and these genes have strong homology. These results suggest that the minor QTL for peanut root-knot nematode resistance on chromosome 15 could be a homolog of the major QTL on chromosome 13.

The high-resolution genetic and physical map of the Rag2 locus will facilitate MAS for this gene from PI 200538 in soybean breeding programs as it has resulted in the identification of SNP markers closely linked to it. The introgression of this gene into new cultivars is important as it provides resistance to SA biotypes 1 and 2 .

The SNP markers we developed will be especially useful in MAS and pyramiding of SA-resistance genes because of their very close proximity to the gene and the availability of efficient SNP marker detection assays. In addition, the identification of the physical location of Rag2 on the soybean chromosome will greatly facilitate the cloning and functional characterization of the gene. The cloning of Rag2 will improve our understanding of SA defense mechanisms in soybean plants. This information also can be applied to compare the function of this gene to other SA-resistance genes such as Ragl or cloned insectresistance genes in other species. We are conducting ongoing studies to clone Rag1 and Rag2.

Acknowledgments This work was supported by soybean check-off funding from the Illinois Soybean Association, the United Soybean Board, and the USDA CSREES grant \#AG2006-34488-16915 to $\mathrm{MEH}$ and BD.

\section{References}

Ashfield T, Bocian A, Held D, Henk AD, Marek LF, Danesh D, Penuela S, Meksem K, Lightfoot DA, Young ND, Shoemaker RC, Innes RW (2003) Genetic and physical localization of the soybean Rpg1-b disease resistance gene reveals a complex locus containing several tightly linked families of NBS-LRR genes. Mol Plant Microbe Interact 16:817-826

Bell-Johnson B, Garvey G, Johnson J, Lightfoot D, Meksem K (1998) Biotechnology approaches to improving resistance to SCN and SDS: methods for high-throughput marker-assisted selection. Soybean Genet Newsl 25:115-117

Brotman Y, Silberstein L, Kovalski I, Perin C, Dogimont C, Pitrat M, Klingler J, Thompson GA, Perl-Treves R (2002) Resistance gene homologous in melon are linked to genetic loci conferring disease and pest resistance. Theor Appl Genet 104:1055-1063

Choi IY, Hyten DL, Matukumalli LK, Song Q, Chaky JM, Quigley CV, Chase K, Lark KG, Reiter RS, Yoon MS, Hwang EY, Yi SI, Young ND, Shoemaker RC, van Tassell CP, Specht JE, Cregan PB (2007) A soybean transcript map: gene distribution, haplotype and single-nucleotide polymorphism analysis. Genetics 176:685-696

Cregan PB, Quigley CV (1997) Simple sequence repeat DNA marker analysis. In: Caetano-Anolles G, Gresshoff PM (eds) DNA markers: protocols, applications and overview. Wiley, New York, pp 173-185

Dogimont C, Bendahmane A, Pitrat M, Burget-Bigeard E, Hagen L, Le Menn A, Pauquet J, Rousselle P, Caboche M, Chovelon V (2009) Gene resistant to Aphis gossypii. US Patent 7,576,264, 18 Aug 2009

Hayes AJ, Yue YG, Saghai Maroof MA (2000) Expression of two soybean resistance gene candidates shows divergence of paralogous single-copy genes. Theor Appl Genet 101:789-795

Hill CB, Li Y, Hartman GL (2004a) Resistance to the soybean aphid in soybean germplasm. Crop Sci 44:98-106

Hill CB, Li Y, Hartman GL (2004b) Resistance to Glycine species and various cultivated legumes to the soybean aphid (Homoptera: Aphididae). J Econ Entomol 97:1071-1077 
Hill CB, Li Y, Hartman GL (2006a) A single dominant gene for resistance to the soybean aphid in the soybean cultivar Dowling. Crop Sci 46:1601-1605

Hill CB, Li Y, Hartman GL (2006b) Soybean aphid resistance in soybean Jackson is controlled by a single dominant gene. Crop Sci 46:1606-1608

Hill CB, Kim KS, Crull L, Diers BW, Hartman GL (2009) Inheritance of resistance to the soybean aphid in soybean PI 200538. Crop Sci 49:1193-1200

Hill CB, Crull L, Herman T, Voegtlin DJ, Hartman GL (2010) A new soybean aphid (Hemiptera: Aphididae) biotype identified. J Econ Entomol 103:509-515

Honeycutt RJ, Sobral BWS, Keim P, Irvine JE (1992) A rapid DNA extraction method for sugarcane and its relatives. Plant Mol Biol Rep 10:66-72

Hulbert SH, Bennetzen JL (1991) Recombination at the RP1 locus of maize. Mol Gen Genet 226:377-382

Hyten DL, Choi I-Y, Song Q, Specht JE, Carter TE, Shoemaker RC, Hwang E-Y, Matukumalli LK, Cregan PB (2010) A high density integrated genetic linkage map of soybean and the development of a 1,536 Universal Soy Linkage Panel for QTL mapping. Crop Sci (in press)

Kaczorowski KA, Kim KS, Diers BW, Hudson ME (2008) Microarray-based genetic mapping using soybean near-isogenic lines and generation of SNP markers in the Ragl aphid-resistance interval. Plant Genome 1:89-98

Kang ST, Mian MAR, Hammond RB (2008) Soybean aphid resistance in PI 243540 is controlled by a single dominant gene. Crop Sci 48:1744-1788

Kim KS, Hill CB, Hartman GL, Mian MAR, Diers BW (2008) Discovery of soybean aphid biotypes. Crop Sci 48:923-928

Kim KS, Bellendir S, Hudson KA, Hill CB, Hartman GL, Hyten D, Hudson ME, Diers BW (2010) Fine mapping the soybean aphid resistance gene Rag1 in soybean. Theor Appl Genet 120:10631071

Klingler J, Creasy R, Gao LL, Nair RM, Calix AS, Jacob HS, Edwards OR, Singh KB (2005) Aphid resistance in Medicago truncatula involves antixenosis and phloem-specific, inducible antibiosis, and maps to a single locus flanked by NBS-LRR resistance gene analogs. Plant Physiol 137:1445-1455

Li Y, Hill CB, Hartman GL (2004) Effect of three resistant soybean genotypes on the fecundity, mortality, and maturation of soybean aphid (Homoptera: Aphididae). J Econ Entomol 97:1106-1111

Li Y, Hill CB, Carlson SR, Diers BW, Hartman GL (2007) Soybean aphid resistance in the soybean cultivars Dowling and Jackson map to linkage group M. Mol Breed 19:25-34

Li Y, Zou J, Li M, Bilgin DD, Vodkin LO, Hartman GL, Clough SJ (2008) Soybean defense responses to the soybean aphid. New Phytol 179:185-195

Martin GB, Bogdenove AJ, Sessa G (2003) Understanding the functions of plant disease resistance proteins. Annu Rev Plant Biol 54:23-61

Mensah C, DiFonzo C, Wang D (2008) Inheritance of soybean aphid resistance in PI 567541B and PI 567598B. Crop Sci 48:1759-1763

Mian MAR, Hammond RB, St Martin SK (2008a) New plant introductions with resistance to the soybean aphid. Crop Sci 48:1055-1061

Mian MAR, Kang ST, Beil SE, Hammond RB (2008b) Genetic linkage mapping of the soybean aphid resistance gene in PI 243540. Theor Appl Genet 117:955-962
Michel AP, Zhang W, Jung JK, Kang ST, Mian MAR (2009) Population genetic structure of Aphis glycines. Environ Entomol 38:1301-1311

Milligan SB, Bodeau J, Yaghoobi J, Kaloshian I, Zabel P, Williamson VM (1998) The root knot nematode resistance gene $M i$ from tomato is a member of the leucine zipper, nucleotide binding, leucine-rich-repeat family of plant genes. Plant Cell 10:13071320

Nickell CD, Noel GR, Cary TR, Thomas DJ, Leitz RA (1999) Registration of 'Ina' Soybean. Crop Sci 39:1533

Rossi M, Goggin FL, Milligan SB, Kaloshian I, Ullman DE, Williamson VM (1998) The nematode resistance gene $M i$ of tomato confers resistance against the potato aphid. Proc Natl Acad Sci USA 95:9750-9754

SAS Institute (2002) The SAS system for Windows. Release 9.00. SAS Institute, Cary

Schmutz J, Cannon S, Schlueter J, Ma J, Mitros T, Nelson W, Hyten D, Song Q, Thelen J, Cheng J, Xu D, Hellsten U, May G, Yu Y, Sakurai T, Umezawa T, Bhattacharyya M, Sandhu D, Valliyodan B, Lindquist E, Peto M, Grant D, Shu S, Goodstein D, Barry K, Futrell-Griggs M, Du J, Tian Z, Zhu L, Gill N, Joshi T, Libault M, Sethuraman A, Zhang X-C, Shinozaki K, Nguyen H, Wing R, Cregan P, Specht J, Grimwood J, Rokhsar D, Stacey G, Shoemaker R, Jackson S (2010) Genome sequence of the paleopolyploid soybean. Nature 463:178-183

Shoemaker RC, Polzin K, Labate J, Specht J, Brummer EC, Olson T, Young N, Concibido V, Wilcox J, Tamulonis JP (1996) Genome duplication in soybean (Glycine subgenus soja). Genetics 144:329-338

Song QJ, Marek LF, Shoemaker RC, Lark KG, Concibido VC, Delannay X, Specht JE, Cregan PB (2004) A new integrated genetic linkage map of the soybean. Theor Appl Genet 109:122128

Tamulonis JP, Luzzi BM, Hussey RS, Parrott WA, Boerma HR (1997) DNA marker analysis of loci conferring resistance to peanut root-knot nematode in soybean. Theor Appl Genet 95:664-670

Van Ooijen JW, Voorrips RE (2001) JoinMap 3.0 software for the calculation of genetic linkage maps. Plant Research International, Wageningen

Voegtlin DJ (2008) United States soybean aphid commentary (online). http://sba.ipmpipe.org/cgi-bin/sbr/public.cgi?host=All\% 20Legumes/Kudzu\&pest=soybean_aphid. Accessed 18 Jun 2009

Wang Z, Dai L, Jiang Z, Peng W, Zhang L, Wang G, Xie D (2005) GmCOI1, a soybean F-box protein gene, shows ability to mediate jasmonate-regulated plant defense and fertility in Arabidopsis. Mol Plant Microbe Interact 18:1285-1295

Wei F, Gobelman-Werner K, Morroll SM, Kurth J, Mao L, Wing R, Leister D, Schulze-Lefert P, Wis RP (1999) The Mla (powdery mildew) resistance cluster is associated with three NBS-LRR gene families and suppressed recombination within a $240-\mathrm{kb}$ DNA interval on chromosome 5S (1HS) of barley. Genetics 153:1929-1948

Witsenboer H, Kesseli RV, Fortin MG, Stanghellini M, Michelmore RW (1995) Sources and genetic structure of a cluster of genes for resistance to three pathogens in lettuce. Theor Appl Genet 91:178-188

Zhang G, Gu C, Wang D (2009) Molecular mapping of soybean aphid resistance genes in PI 567541B. Theor Appl Genet 118:473-482 